\title{
The Connotation, Measurement and Function of Presenteeism
}

\author{
Li Guang \\ Baoshan University, Baoshan Yunnan, 678000
}

\begin{abstract}
Presenteeism can bring about physical and mental health risks to the individuals and it can cause organizational productivity loss. Based on the analysis focusing on foreign research literature, analyzing presenteeism from the aspects of its connotation, theoretical framework, measurement methods, antecedents and outcome variables and so on, this thesis explores the impact of different variables on the act of presenteeism, and tries to construct the occurrence mechanism of presenteeism. Meanwhile, suggestions on theoretical construction, indigenous research, special group research, method and tool development, quantification of productivity loss and currency conversion are made for future research.
\end{abstract}

Keywords-Presenteeism; Health; HRM; Organizational behavior

\section{INTRODUCTION}

From 1990s, presenteeism is getting more and more attention. Presenteeism refers to the practice of coming to work despite illness [1-2], often resulting in a lot of negative effects to the organization. The survey shows that employees in Canada, Sweden, Denmark and other countries all involved in presenteeism. Presenteeism increases the risk of illness of employees [3] and additional costs [4] for the enterprise.

With the development of globalization, the labor market faces more complicated situations, and the health of the employees, the organizational behavior and HRM face more challenges. There will be new characteristics and tendencies in presenteeism in different regions. And presenteeism of employees is bound to become a new problem. Strengthen the indigenous research and cross-culture study of presenteeism on the basis of the previous study and explore correlated variables of it are especially important

\section{THEORETICAL FRAMEWORK OF PRESENTEEISM}

Johns believes that presenteeism is an act between total attendance and absence, and personal factors (work attitude, personality, fairness, pressure, legitimacy perception of absenteeism, ill role orientation, internal and external control of health and gender) and situational factors (work requirements, work alternatives, team work; attendance and absence culture of an organization, absence policy and incentive system of an organization, etc. are important factors that influence the decision of presenteeism. Johns (2010) pointed out that individual's attendance decision with illness would bring consequences with different degrees to the employee himself

Author introduction: Li Guang, BaoShan University Education School lecturer, research direction: human resources development and management

Project: The achievements of "Empirical research on the quality of employment evaluation index of Yunnan minority nationality college students” (project number: 2016QN04) of the employment and entrepreneurship university graduates in the education department of yunnan province. and the organization. Lin Huiyan and Lu Luo supplemented the analysis of the social and economic background variables of the individuals, and divided the antecedents of presenteeism into economic and family factors, personality and attitude factors and work situation factors. Sun Jianmin and Zhang Yejun focused on the division of the antecedents of presenteeism, which included the four parts of individual factors (physical conditions, demographic variables, and personality traits), work-related factors (work characteristics, work attitude, and work experience), organization-level factors (organizational culture, management system, and leadership) and team-level factors (the relationship between colleagues, social support, and teamwork) and they also analyzed the outcome variables, which included individual health (physical and mental health), work (productivity, absenteeism, satisfaction, job burnout and job performance) and organizational level (organizational productivity).

From the perspective of theoretical framework, Johns first constructed the theory system of presenteeism, which laid the foundation for the further study. However, the variables are incomplete and lack of empirical research support. The indicators of the theory design of Lin Huiyan and Lu Luo are more comprehensive, which considered the motivational factors of presenteeism. However, the research is not deep enough and the analysis of variables is incomplete and it lacks of the deep exploration of motivational factors. The analysis of variables in the theory of Sun Jianmin and Zhang Yejun is more specific and it is in line with the actual situation of the workplace in China theoretically. At the same time, the motivation factors are considered, and they are scientific. However, the research on related variables in China is very scarce and it is difficult to get the empirical support.

\section{MEASUREMENT OF PRESENTEEISM}

\section{A. Measurement of Act of Presenteeism}

Aronsson et al., firstly used the self-report method to measure the employee's presenteeism, asking the subjects to recall the frequency of their working even being sick in the past 12 months [2]. The scoring formula of " $0-1$ " bisection method was adopted for the statistics, and it is used by the researchers for a long time. Lu, Lin and Cooper adopted the 4-grade scoring formula while Johns adopted the 5-grade scoring formula [1]. Caverley et al. and Johns proposed the measurement of presenteeism through the adoption of the specific days that an employee works while sick. 


\section{B. Measurement of Productivity of Presenteeism}

Through the analysis of the four indicators of number of questions, the recall time, the scoring formula and the comments, it is found that Stanford Presenteeism Scale (SPS-6 in short) and Work Limitations Questionnaire are the most representative scale[5] for the measurement of productivity loss of presenteeism. SPS-6 asks the subjects to assess the consistency between the contents of the project and the health, attendance and work conditions of an individual and it is of good reliability and validity. WLQ requires the subjects to report their physical conditions that need medicine or the treatment of a doctor and assesses the influence that they bring to the four dimensions of time management, body movement, psychological and interpersonal activities and work productivity and the reliability and validity are verified.

\section{Currency Conversion of Productivity Loss of presenteeism}

When an employee works while sick, its productivity is between 0-100percent [1]. Brooks et al. tried to convert productivity loss into a specific amount of money [5]. And the approaches include the three ones of human capital approach, team production approach and enterprise self-assessment approach. There are three main ways to calculate the unit cost of productivity loss in the process of currency conversion for the productivity loss: the payment method of loss conversion through multiplying invalid working hours by unit payment; the team production method of loss conversion through multiplying invalid working hours by unit payment and multiplying payment coefficient; and the online assessment tools method of the economic loss assessment of productivity by professional agencies.

The author believes that the measurement of presenteeism shall pay attention to the distinction of the two levels of the act and productivity. Different methods have their own focus and the data provided by the subjects and the organizations that they work at shall be combined with. In the behavior measurement, the test of the subjects shall be the main and the data provided by the organization shall be the supplement; in the productivity loss measurement, the data provided by the organization shall be the main while the test of the subject shall be the supplement. And, as of the recall period, it shall be divided according to different types of diseases. In particular, many diseases are of seasonal features and a 12-month period is suggested for reference. Besides, the research on presenteeism carried out on the basis of an individual's health event can deepen the problem analysis from different perspectives and can avoid the troubles caused by scoring and conversion.

\section{ANTECEDENTS OF PRESENTEEISM}

\section{A. Individual Factors}

Physical and psychological health. Many studies have found that employees with back and neck pain, respiratory tract infection, allergy, nasosinusitis, asthma, gastro-esophageal reflux disease, dermatitis, muscular problems, anxiety disorders, fatigue and mild depression, headache, digestive disorders have a higher degree of presenteeism[2][6]. The presenteeism of the employees with depressive disorders and anxiety disorders is twice of that of other employees [6].

Age and gender. Older employees show high presenteeism [7]. Female shows more presenteeism than male [2].

Education level. The education level of the employees has a negative correlation with presenteeism [2].

Economic conditions. Employees with low salaries have higher presenteeism [2].

\section{B. Organizational Factors}

Enterprise culture. Enterprise culture can influence the presenteeism of the employees in an organization [1].

Rules and regulations. The traditional sick leave system can promote the phenomenon of presenteeism. Collins found that punitive measures in the rules and regulations had a compelling impact on an employee's presenteeism.

Leader supporting. Demerouti E believed that leader supporting can reduce presenteeism and alleviate the job burnout caused by presenteeism.

\section{Vocation Factors}

Working pressure. Working pressure can influence an employee's presenteeism [8] and Gosselin and Taloyan have verified this.

Job requirements. Demerouti et al., Leineweber et al., Deery, Walsh and Zatzick found that presenteeism is positively related to job requirements.

Individual's working attitude. Employees with more physical and mental inputs show a higher level of presenteeism [8]. Family ecosystem and presenteeism are negatively related [7]. Presenteeism and fairness are negatively related [1].

Job insecurity. Job insecurity is a significant variable to predict presenteeism [1] [7]. Taifor et al. have found that job insecurity plays a regulatory role in job requirements and presenteeism. Demerouti, Deery, Walsh and Zatzick have found that conflict job requirements and time pressure [9] are all related to presenteeism [1] [2] [7]. 


\section{Team Factors}

Grinyer and Singleton have found that the team work and colleague pressure factors in an organization can influence the presenteeism of an employee. The employee with more colleague support shows a higher presenteeism than that of an employee who lacks of the support from colleagues.

\section{E. Behavioral Motivation of Presenteeism}

Johansen, Aronsson and Marklund have found 12 motivations that influence presenteeism through studies. Johansen et al. have found the highest motivations that influence presenteeism are that "I do not want to increase the burden on my colleagues", "I like working" and "Others cannot complete my duties".

\section{OUTCOME VARIABLES OF PRESENTEEISM}

\section{A. Organizational Variables}

Productivity loss. Presenteeism is related to productivity loss [10]. Weaver has pointed out that the presenteeism loss of American employees exceeds the capital expenditure of absence, medical treatment and welfare of the disabled.

\section{B. Operating working Variables}

Absence of employees. Deery, Walsh, Zatzick, Taloyan et al., Poms and Sendén and so on all have confirmed the positive correlation between presenteeism and the subsequent absence behavior.

Job satisfaction. A survey in Taiwan of China of Lu L and Lin H Y and so on shows that the higher the presenteeism of employees, the higher the job dissatisfaction might be.

Job burnout. The research of Ferreira and Martinez shows that there is a positive correlation between the presenteeism of primary school teachers and the job burnout.

Work performance. The work performance of employees measured by boss evaluation by Miraglia shows that there is a significant positive correlation between presenteeism and work performance.

\section{Personal Variables}

Physical and psychological health. Kivimäki et al. has found that the incidence of coronary artery disease of employees with high presenteeism is twice than that of employees with low presenteeism. The higher the presenteeism, the worse the employees' health conditions.

Job burnout. The relationship between presenteeism and job burnout can be adjusted by leader supporting level.

Restricted work. Liu Yongli has found that improve the psychological consistency of nurses can alleviate the restricted work and Dong Xiaofang has found that improve the psychological authorization level can improve the work efficiency.

\section{CONCLUSION}

\section{A. Theoretical Construction of Presenteeism}

Although there is a lot of empirical support on relevant studies on presenteeism at abroad, the research on its occurrence mechanism, antecedents and outcome variables and so on has not been reasonably and completely explained. Relevant theory guidance is required to the study on presenteeism considering the factors of health characteristics, job insecurity, working attitude and experience, personality and social dynamics and so on comprehensively [1]. Lin Huiyan and Lu Luo (2013) have pointed out that "pressure sourceresponse- pressure perception" and "motivation- behaviorconsequence" shall be combined together as the conceptual framework to rationalize the cause and effect of presenteeism. Under the presenteeism conditions, personal factors, organizational factors, working characteristics, team characteristics, social, political and economic culture shall be treated as antecedents, the need and motivation of personal factors shall be treated as intervening variables, and the productivity loss, the performance reduction, and the increased cost, and the health damage, etc. shall be treated as outcome variables to consider and construct the theoretical model of "antecedents--motivation, through need--presenteeism-outcome variables" and other moderator variables to consider and discuss the relationship among variables of presenteeism.

\section{B. Indigenous Research of Presenteeism}

The study on presenteeism in China is at the initial stage and the research literature is relatively few. The research findings under Chinese culture background of Lin Huiyan and Lu Luo (2013) have significant difference with that of the western. Under the influence of traditional culture, and under the impact of the globalization culture, the presenteeism of Chinese may show different characteristics and levels. Chinese has been influenced by Confucian culture for a long time and in the work concept based on Confucian culture, "work hard", "endurance" and "perseverance" take a very important position.

According to the study, it can be learned that Chinese employees may show presenteeism of higher level than western employees in order to show and keep the traditional virtues of hardworking, persistence and loyalty. Compared with presenteeism in western culture, the connotation and motivation in Chinese culture might be different. It is necessary to explore the presenteeism of indigenous employees in the future study.

\section{Focus on Key Industries and Special Groups' Research}

The presenteeism of employees has obvious differences due to industry, organization type and occupational. The future research shall focus on the research of presenteeism of special industries and special groups, such as the presenteeism of executives of private enterprises, people's teachers, IT elites, nurses, civil servants and soldiers to explore the positive coping strategies of presenteeism. 


\section{Development of Research Techniques and Measurement Tools of Presenteeism}

The existing studies mainly use the subjective response method of employee's recall, self-report, and gap filling, as well as the scoring method of categorical scoring and assignment conversion, which may be easily influenced by social desirability, numeric conversion and the reliability and validity of the scale. In the future, the study shall focus on the development of generic scales and pay more attention to the presenteeism behavior itself and adopt the continuous scoring mode. The longitudinal research method shall be tried to improve the reliability and validity of the research and analyze the relationship between presenteeism and relevant variables of individual's health in deep.

As of researches in China, we shall pay attention to apply the relatively mature measurement tools at abroad, expand the empirical research in China, and verify the applicability of the measurement tools in China.

\section{E. Explore the Quantification of Indigenous Productivity Loss and Currency Conversion}

One of the important issues of the presenteeism research is to explore the productivity loss situation and the burden that it causes to an individual and an enterprise. Different culture backgrounds result in different outcomes. However, most of the existing researches get the loss amount through calculating invalid working hours and the application of payment method and there are many disputes. The follow-up study shall focus on these issues and form a consistent standard and a complete standard system gradually, which is beneficial to the horizontal and longitudinal comparison of the study.

\section{REFERENCES}

[1] Johns, G. Presenteeism in the workplace: A review and research agenda. Journal of Organizational Behavior,2010,31(4),519-542.

[2] Aronsson G, Gustafsson K, Dallner M. Sick but yet at work. An empirical study of sickness presenteeism. Journal of Epidemiology and Community Health, 2000, 54(7): 502-509.

[3] Kivimäki,M.,Head,J.,Ferrie,J.E.,Hemingway,H.,Shipley,M.J.,Vahtera,J., \&Marmot,M.G..Working while ill as a risk factor for serious coronary events: The Whitehall II study. American Journal of Public Health, 2005,95(1), 98-102.

[4] Goetzel RZ, Long SR, Ozminkowski R J,et al. Health, Absence, Disability, and Presenteeism Cost Estimates of Certain Physical and Mental Health Conditions Af-fecting US Employers [J]. Journal of Occupational and Environmental Medicine,2004,46(4):398-412.

[5] Brooks A, Hagen SE, Sathyanarayanan S,et al. Presen-teeism:Critical Issues[J]. Journal of Occupational and Environmental Medicine,2010,52(11):1055-1067.

[6] Druss, B. G.,Schlesinger,M.,\& Allen, H. M.. Depressive symptoms, satisfaction with health care,and 2-year work outcomes in an employed population. American Journal of Psychiatry,2001,158(5),731-734.

[7] Hansen C D,Andersen J H.Going ill to work-What personal circumstances,attitudes and work-related fac-tors are associated with sickness presenteeism?Social Science \& Medicine,2008,67(6):956-964.

[8] Biron C, Brun J P,Ivers H,et al.At work but ill:Psychosocial work environment and well - being determi-nants of presenteeism propensity. Journal of Public Mental Health,2006,5(4):26-37.

[9] Caverley,N, Cunningham,J.B., \& MacGregor,J.N. Sickness presenteeism,sickness absenteeism, and health following restructuring in a public service organization. Journal of Management Studies,2007, 44(2),304-319.

[10] Schultz, A. B., Chen, C. Y., \& Edington, D. W. The cost and impact of health conditions on presenteeism to employers.Pharmacoeconomics, 2009, 27(5),365-378. 